\title{
Inhibition of Quorum Sensing System in Pseudomonas aeruginosa by Psammaplin A and Bisaprasin Isolated from the Marine Sponge Aplysinella rhax
}

Emmanuel T. Oluwabusola, ${ }^{\mathrm{a}^{*}}$ Nursheena Parveen Katermeran, ${ }^{\mathrm{b}}$ Lik Tong Tan, ${ }^{\mathrm{b}^{*}}$ Oluwatofunmilayo Diyaolu, ${ }^{\text {a }}$ Jioji Tabudravu, ${ }^{\mathrm{c}}$ Rainer Ebel, ${ }^{\mathrm{a}}$ and Marcel Jaspars, ${ }^{\mathrm{a}}$

${ }^{a}$ Marine Biodiscovery Centre, Department of Chemistry, University of Aberdeen, AB24

3UE, Old Aberdeen, United Kingdom.

${ }^{b}$ Natural Sciences and Science Education, National Institute of Education, Nanyang Technological University, 1 Nanyang Walk, Singapore, 637616, Singapore.

${ }^{\mathrm{c} S c h o o l ~ o f ~ F o r e n s i c ~ a n d ~ A p p l i e d ~ S c i e n c e s, ~ F a c u l t y ~ o f ~ S c i e n c e ~ a n d ~ T e c h n o l o g y, ~ U n i v e r s i t y ~ o f ~}$ Central Lancashire, Preston, PR1 2HE, United Kingdom.

Running headline: Marine-derived antiquorum sensing inhibitors.

Corresponding author: Emmanuel T. Oluwabusola, Department of Chemistry, Meston

Building, Meston Walk, Aberdeen AB24 3UE, Scotland, United Kingdom. Email:

r01eto16@abdn.ac.uk. Tel: +44 (0)1224 272943

\section{Significance and Impact of the Study:}

The attention of the scientific community has been drawn to using marine sources to find novel quorum sensing inhibitors as antipathogenic drugs to combat antimicrobial resistance and pathogenesis caused by the proliferation of pathogenic bacteria mediated by the quorum sensing (QS) system. By blocking the QS signalling communication, the ability to assemble an organised community structure that enables drug resistance and production of virulence factors will be attenuated. The significance of this investigation is based on the discovery of bromotyrosine derivatives as potential new drug leads for the development of antipathogenic agents.

\section{Abstract}

Natural products isolated from marine sponges have exhibited profound bioactivity and, in some cases, serve as potent quorum sensing inhibitory agents by preventing microbial biofilm 
formation. In this study, the inhibitory potential of the psammaplin type compounds, psammaplin A (1) and bisaprasin (2), isolated from the marine sponge, Aplysinella rhax, was evaluated in the quorum-sensing inhibitory assay based on the Pseudomonas aeruginosa PAO1 lasB-gfp and P. aeruginosa PAO1 rhlA-gfp biosensor strains. The result indicated that psammaplin A (1) showed moderate inhibition against lasB-gfp biosensor strains but significantly inhibited the QS-gene promoters, $r h l A-g f p$ with $\mathrm{IC}_{50}$ value at 30.69 and $2.64 \mu \mathrm{M}$, respectively. In contrast, bisaprasin (2) displayed significant inhibition for both biosensor strains, lasB-gfp and $r h l A-g f p$ with $\mathrm{IC}_{50}$ values at 8.70 and $8.53 \mu \mathrm{M}$, respectively. To our knowledge, the antiquorum sensing activity of these marine-derived bromotyrosine compounds is described here for the first time.

Key words: Quorum sensing, marine sponge, Pseudomonas aeruginosa, psammaplin.

\section{Introduction}

The discovery of antibiotics in the early 20th century was life-saving for people suffering from infectious diseases( Aminov et al. 2010). Despite the progress made in drug development, there is a high demand for better strategies to tackle the widespread threat of antibiotic-resistant microorganisms. Unfortunately, many common community-acquired pathogenic bacteria, such as Escherichia coli, Klebsiella pneumoniae, Salmonella, methicillin-resistant Staphylococcus aureus and Pseudomonas aeruginosa, have shown progressive resistance to conventional drugs. A World Health Organisation (WHO) report in 2019 concluded that if the current trend is not averted drug-resistant diseases could lead to the death of 10 million people each year by 2050 ( Raymond and Powell 2019; Dai et al. 2019).

Intensive research in bacterial cellular functions implicates the quorum sensing system as the major contributor to their continual pathogenesis and drug resistance. Quorum sensing (QS) is a cell-to-cell communication system exhibited by most microorganisms in response to their 
cell density ( $\mathrm{Ng}$ and Bassler, 2009). The QS system involves the secretion of chemical signalling molecules to monitor population density within bacterial communities. As the bacterial colony size increases, it generates a sufficient number of signal molecules to activate a variety of downstream cellular processes, including biofilm formation, virulence factors, and drug resistance mechanisms( Zhao et al. 2020). QS signalling of pathogens represents the central regulatory mechanism for the expression of virulence determinants, such as proteases, elastases, exotoxins, rhamnolipids and many other immune-evasion molecules ( Pamp and Tolker-Nielsen 2007; Chen et al. 2013). For instance, P. aeruginosa possesses four functional QS systems consisting of LasI/LasR, Rhll/RhlR pseudomonas quinolone signal (PQS) and the integrated quorum-sensing signal (IQS) ( Davies 1998; Jakobsen et al. 2013). LasI/LasR and Rhll/RhlR circuit homologs are the two acyl homoserine lactone (AHL)-dependent QS system in $P$. aeruginosa ( Wagner et al. 2006). The interaction of AHLs, namely $N$-3-oxododecanoyl homoserine lactone and $\mathrm{N}$-butyryl-homoserine lactone, with the respective receptors, lasR and rhIR, activates the transcription of nearly $10 \%$ of about 300 genes in $P$. aeruginosa. (Schuster and Peter, 2006). In addition, cell-to-cell signaling controlled the expression of las $B$ and rhlA genes, which encodes for the major virulence factor, elastase and rhamnolipids, respectively (Pesci et al. 1999; Rasmussen and Givskov, 2006).

Studies have shown that biofilm forming microorganisms exhibit far more resistance to antibiotics than their planktonic counterparts (Rutherford and Bassler 2012). Rhamnolipids are amphipathic glycolipids and are produced through the $r h l A B$ operon and $r h l C$. These compounds plays multiple functions in the maturation and preservation of biofilms by assisting in the formation of microcolony and extracellular polymeric substances (EPS) that are embedded in the bacterial community (Rahim et al. 2001; Davey et al. 2003; Pamp and TolkerNielsen, 2007). The biofilm mode of development serves as a survival strategy for pathogenic microorganism to increase antibacterial resistance and cause severe systemic infections ( Chen 
et al. 2018). A study conducted by Davies and co-workers revealed a correlation between signalling molecules and biofilm development in Pseudomonas aeruginosa and has paved the way for further biofilm research (Davies 1998). As such, interference of the QS system in pathogenic bacteria represents an attractive target for the development of novel therapeutics. For instance, the use of small molecules as potential inhibitors against QS mediated genes responsible for virulence determinants and biofilm formation is an effective strategy in combating microbial resistance to conventional antibiotics (Dai et al. 2019).

Several marine-derived natural products have shown considerable potential as quorum sensing inhibitors, for example manoalide, secomanoalide and manoalide monoacetateisolated from the marine sponge, Luffariella variabilis, exhibited potent QS inhibition against lasB-gfp (ASV) biosensor with $\mathrm{IC}_{50}$ values at $0.66 \mu \mathrm{M}, 1.11 \mu \mathrm{M}$ and $1.12 \mu \mathrm{M}$, respectively ( Skindersoe el al. 2007). In addition, aplyzanzines C-F, a series of bromotyrosine alkaloids isolated from the French Polynesian sponge Pseudoceratina $n$. sp., showed quorum sensing inhibition against the wild typed $V$. harveyi strain (Tintillier et al. 2020).

In our search from marine sources for novel quorum sensing antagonists against QS lasB and rhlA genes promoters responsible for virulence factors and biofilm formation in $P$. aeuroginosa, we tested psammaplin A (1) and bisaprasin (2) (Rodriguez et al. 1987; Jimenez and Crews, 1991; Park et al., 2003). The compounds were previously isolated alongside psammaplins B-D (Rodriguez et al. 1987; Jimenez and Crews, 1991; Park et al., 2003) and OP, 3-bromo-2-hydroxyl-6-carbomethoxy benzoic acid (Oluwabusola et al. 2020), 2-(3-bromo4-hydroxyphenyl) aceto-nitrile and 3-bromo-4-hydroxybenzoic acid from the methanolic extract of the marine sponge, Aplysinella rhax, collected from the Fiji islands and were subjected to QS inhibitory screening. Psammaplin A (1) is composed of two modified amino acids: a bromotyrosine containing an oxime group, and cysteamines that form the disulfide bridge (Rodriguez et al. 1987). The bromotyrosine compound (1) and its derivatives have 
shown to possess good cytotoxicity against ovarian tumour cell lines (Tabudravu et al. 2002), considerable antibacterial activity against gram-positive methicillin-resistant $S$. aureus, inhibition of DNA synthesis and the supercoiling activity of DNA gyrase( Kim et al. 1999), and antiparasitic activity (Oluwabusola et al. 2020). The current study was conducted against the backdrop of interesting biological activities of these type of bromotyrosine compounds.

Herein we report for the first time the inhibitory activity against the QS genes promoters associated with $P$. aeruginosa POA1 by psammaplin A (1) and its biphenylic dimer, bisaprasin (2).

\section{Results and Discussion}

The marine sponge extract was partitioned between water and dichloromethane $(50 \% \mathrm{v} / \mathrm{v})$ using a modified Kupchan method previously described (Oluwabusola et al. 2020) and the $\mathrm{CH}_{2} \mathrm{Cl}_{2}$ fraction was further fractionated using reversed-phase solid-phase extraction (SPE). The resulting 100\%SPE fraction was purified on reversed-phase HPLC to yield $\mathbf{1}$ (5.4 mg) and $2(5.6 \mathrm{mg})$.

\subsection{Structure Elucidation}

The structure of psammaplin A (1)( Figure S1-S6) and bisaprasin (2) (Figure S7-S10) were assigned based on the interpretation of their experimental NMR and HRESIMS data and by comparison with the published data.<smiles>O=C(NCCSSCCNC(=O)/C(Cc1ccc(O)c(Br)c1)=N/O)/C(Cc1ccc(O)c(Br)c1)=N/O</smiles><smiles>O=C(NCCSSCCNC(=O)/C(Cc1cc(O)c(O)c(-c2cc(C/C(=N\O)C(=O)NCCSSCCNC(=O)/C(Cc3ccc(O)c(Br)c3)=N/O)cc(Br)c2O)c1)=N/O)/C(Cc1ccc(O)c(Br)c1)=N/O</smiles> 
The anti-QS activities of the bromotyrosine-containing compounds, $\mathbf{1}$ and $\mathbf{2}$, were evaluated based on biosensor strains $P$. aeruginosa POA1 quorum sensing-controlled lasB and rhlA promoters fused to an unstable gfp (ASV) reporters. The rationale behind this approach was that the growth of the bacteria in the control medium produces signal molecules at a specific threshold that induced the expression of QS-promoters genes leading to an increase fluorescence recorded every $15 \mathrm{~min}$ for a period of $17 \mathrm{hrs}$. For the tested compounds to show inhibition in a dose-dependent manner, it must attenuate the expression of the genes indicated by a reduced fluorescence activity.

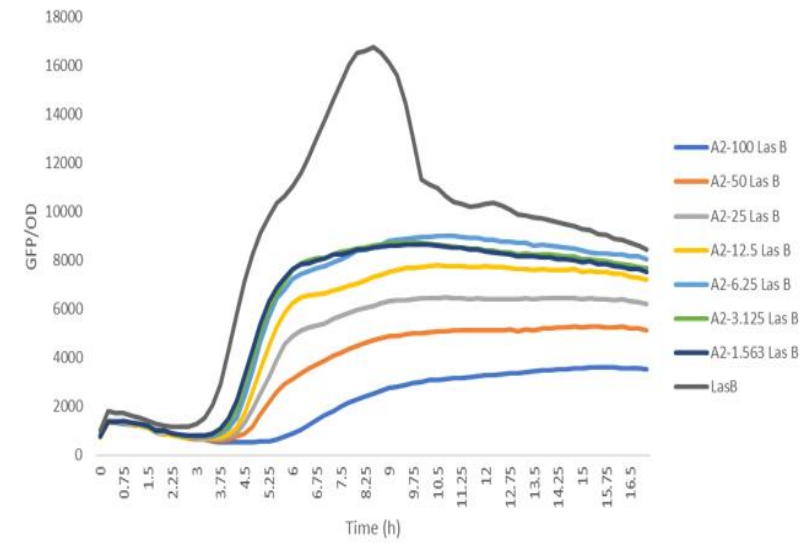

A

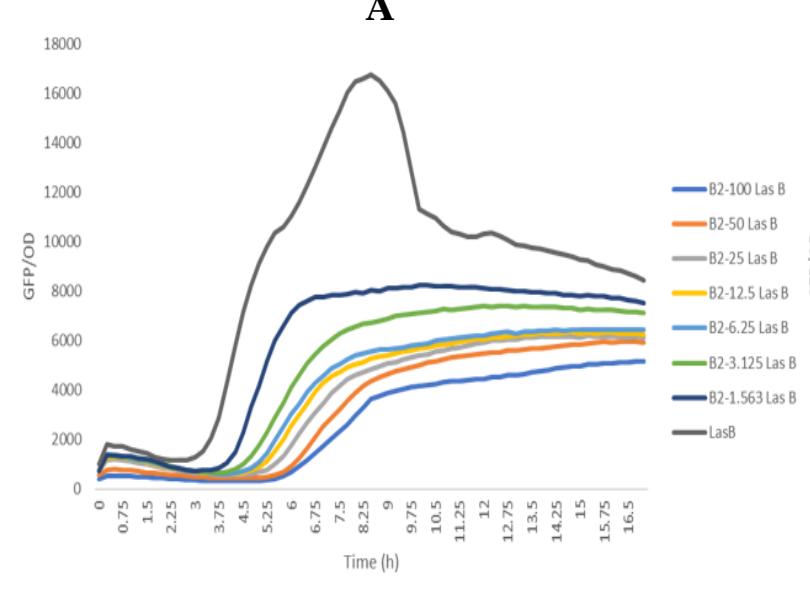

C

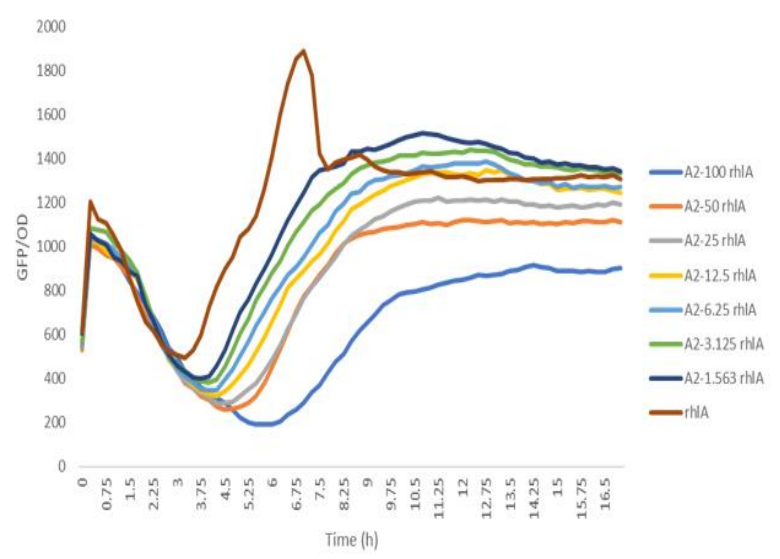

B

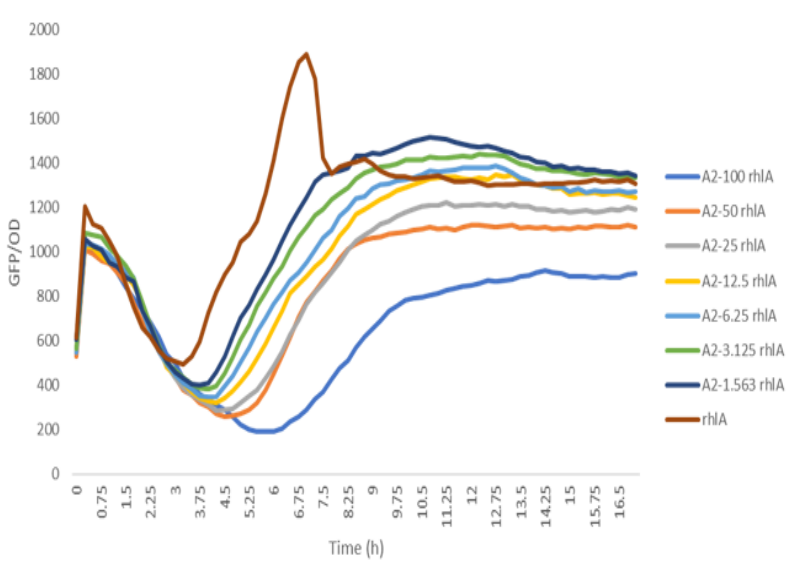

D

Figure 1. (A) and (B) are dose-response curves of psammaplin A (1) when incubated with $P$. aeruginosa PAO1 LasB-gfp(ASV) and rhlA-gfp (ASV) biosensor strains, respectively. (C) and (D) are dose-response curves of bisaprasin (2) when incubated with $P$. aeruginosa PAO1 LasB-gfp(ASV) and $r h l A-g f p(\mathrm{ASV})$ biosensor strains, respectively. 
Table 1. Quorum sensing inhibitory activity of psammaplin A and bisaprasin against $P$. aeruginosa POA1 biosensor strains.

\begin{tabular}{ccc}
\hline \multirow{2}{*}{ Compound } & \multicolumn{2}{c}{$\mathrm{IC}_{50}$ values $(\mu \mathrm{M})$} \\
\cline { 2 - 3 } & lasB-gpf & rhlA-gpf \\
\hline $\mathbf{1}$ & 30.69 & 2.64 \\
\hline $\mathbf{2}$ & 8.53 & 8.70 \\
\hline
\end{tabular}

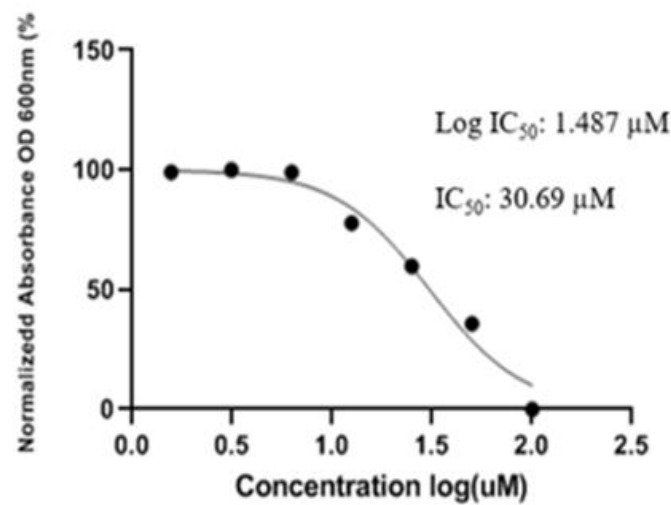

A

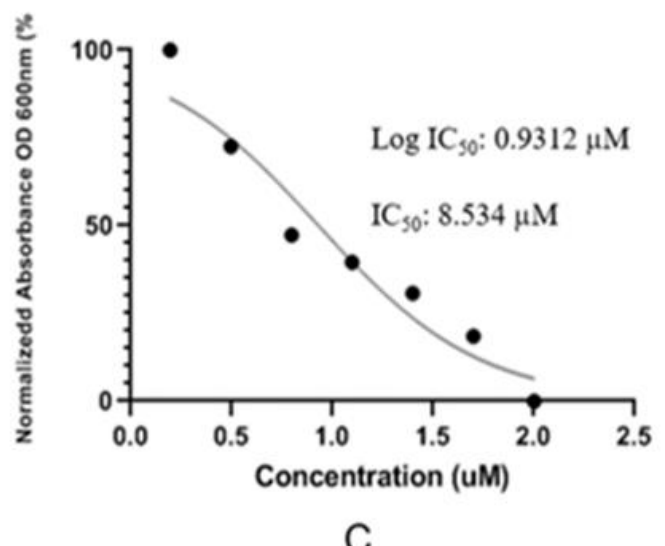

C

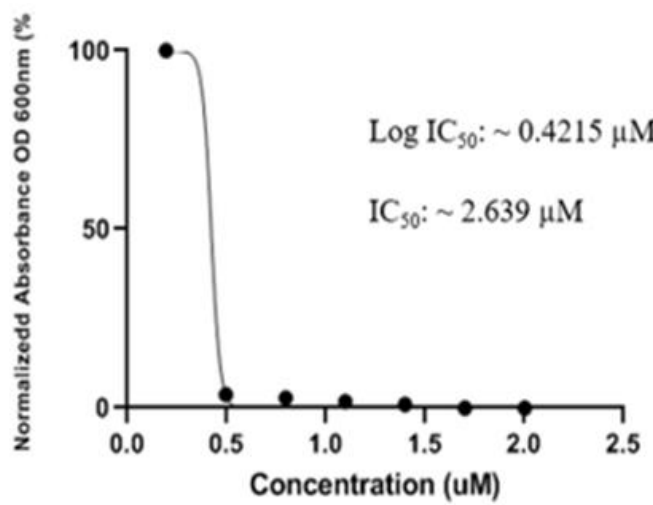

B

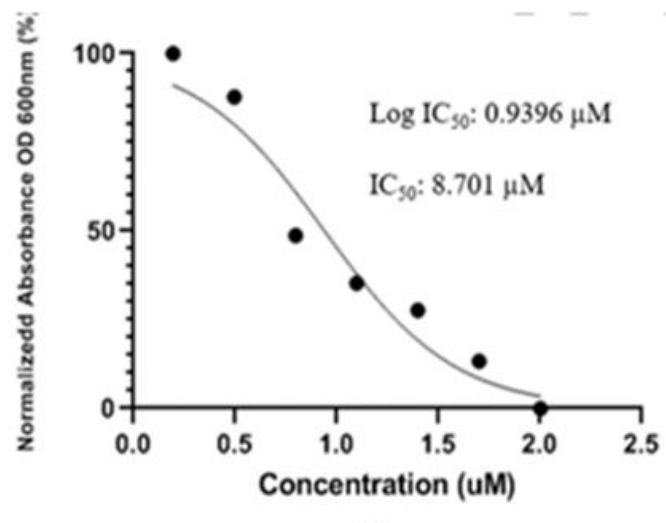

D

Figure 2. (A) and (B) are $\mathrm{IC}_{50}$ curves of psammaplin A (1) against $P$. aeruginosa PAO1 lasB-gfp(ASV) and $r h l A-g f p$ (ASV) biosensor strains, respectively. (C) and (D) are $\mathrm{IC}_{50}$ curves of bisaprasin (2) against P. aeruginosa PAO1 lasB-gfp(ASV) and rhlA-gfp (ASV) biosensor strains, respectively.

Therefore, the dose-dependent assay against gfp-tagged $P$. aeruginosa QS-controlled las $B$ and rhlA promoters were determined at the concentration ranging from $100 \mu \mathrm{M}$ to $1.563 \mu \mathrm{M}$. The dose-response curves of psammaplin A (1) and bisaprasin (2) when incubated with the $P$. aeruginosa PAO1 lasB-gfp(ASV) and $r h l A-g f p(\mathrm{ASV})$ strains are displayed in Figure 1 . The 
GFP expression was measured in relative fluorescence units and normalised by dividing the GFP values by the corresponding OD600 value measured at that time point.

The control of this experiment had the highest GFP-per-OD values, which refer to the PAO1 strain grown without the test compounds. The experiment was performed in triplicate, and the results showed significant QSIs for both compounds in a dose-dependent manner (Figure 1). The half-maximal inhibitory concentration $\left(\mathrm{IC}_{50}\right.$ values) for the two compounds, $\mathbf{1}$ and $\mathbf{2}$, were calculated from the dose-response curve by using Graphpad Prism 6 software package (See Figure 2). The results were obtained in a low micromolar range for $\mathbf{1}$ and $\mathbf{2}$, showing the most significant inhibition with the $\mathrm{IC}_{50}$ values at $2.64 \mu \mathrm{M}$ and $8.53 \mu \mathrm{M}$ against the $P$. aeruginosa PAO1 rhlA-gpf and lasB-gpf biosensor strains, respectively (Table 1). By comparing the overall inhibition, $\mathbf{2}$ was more potent across the board, while $\mathbf{1}$ exhibited specific inhibition against $r h l A$-gpf biosensor strain and moderate inhibition was observed with $\mathrm{IC}_{50}$ value at 30.69 $\mu \mathrm{M}$ against the expression of lasB-gpf biosensor strain. The higher potency of $\mathbf{2}$ could be due to the dimeric nature of the molecule as compared to 1 .

The preliminary report by Davies and co-workers concluded that las QS system is vital in the maturation and differentiation of pathogenic bacterial biofilms as well as the expression of virulence determinant, including proteases, elastase, exotoxins and many other immuneevasion molecules (Pamp and Tolker-Nielsen 2007; Chen et al. 2013). Although the two brominated compounds, $\mathbf{1}$ and $\mathbf{2}$, have not been screened against the biofilm formation of $P$. aeruginosa, it was reported that $\mathbf{1}$ and other oxime-bearing bromotyrosine derivatives, such as bastadins 3-5 and aplysamine, exhibited pronounced biofilm formation inhibition effect of Balanus improvises ( Ortlepp et al. 2007). Moreso, it was established in the literature that over one hundred and thirty molecules isolated from sponges exhibited antifouling activities on diverse microorganisms or invertebrate larvae (A Database of the Marine Natural Products Literature, 2020). Based on the results obtained in this investigation together with the literature 
on the antibiofilm formation stated above, we have of the opinion that the mode of action of the psammaplin type compounds is likely to be interaction with the QS system of the microorganism.

\section{Materials and Methods}

\subsection{General Experimental Procedures}

IR spectra were recorded on a PerkinElmer UATR Two, model L1600300. Both 1D and 2D NMR data were recorded on a Bruker AVANCE III HD Prodigy TCI cryoprobe at 600 and 150 $\mathrm{MHz}$ for ${ }^{1} \mathrm{H}$ and ${ }^{13} \mathrm{C}$, respectively. HRESIMS data were obtained using a ThermoScientific LTQ XL/LTQ Orbitrap Discovery coupled to a Thermo instrument Accela HPLC system, and an Agilent 6540 HRESI-TOF-MS coupled to an Agilent 1200 HPLC system. This procedure was explained in detail in the previous publication (Oluwabusola et al. 2020).

\subsection{Collection and Identification}

The sponge sample was collected from the Fiji Islands in December 1997, freeze-dried and stored in $4^{\circ} \mathrm{C}$. It was identified as Aplysinella rhax by Dr. John Hooper of the Queensland Centre for Biodiversity, Queensland Museum, Australia as described in a previous publication (Tabudravu et al. 2002). A voucher specimen (Voucher number: 9712SD130) is held at the Pacific Regional Herbarium at the University of the South Pacific, Suva, Fiji Islands.

\subsection{Extraction and Isolation of Psammaplin A (1) and Bisaprasin (2).}

The sponge sample was extracted with $\mathrm{MeOH}(3 \times 300 \mathrm{~mL})$ followed by DCM $(3 \times 200 \mathrm{~mL})$, dried and partitioned following the modified Kupchan liquid-liquid partitioning technique described previously (Kupchan et al. 1978). The four fractions (sec-butanol fraction, methanol fraction, $\mathrm{CH}_{2} \mathrm{Cl}_{2}$ fraction and hexane fraction) were dried and weighed. The process of fractionation and purification that led to the isolation of compound $\mathbf{1}(5.4 \mathrm{mg})$ and compound 
2 (5.8 mg) from the $\mathrm{CH}_{2} \mathrm{Cl}_{2}$ fraction was detailed in the previous publication (Oluwabusola et al. 2020).

\subsection{P. aeruginosa QS. Inhibition Assays.}

The bromotyrosine compounds, $\mathbf{1}$ and 2, were dissolved in 100\% DMSO and mixed with ABTGC medium (AB minimal medium containing $2.5 \mathrm{mg} /$ litre thiamine, supplemented with $0.2 \%(\mathrm{wt} / \mathrm{vol})$ glucose and $0.2 \%$ (wt/vol) Casamino Acids), after which they were added to the first column of wells of a 96-well microtiter plate to give a final concentration of $100 \mu \mathrm{M}$ in a final volume of $200 \mu \mathrm{L}$. One hundred microliters of ABTGC medium was then added to the remaining wells in the plate, and serial 2-fold dilutions of the inhibitors were made by adding $100 \mu \mathrm{L}$ of the preceding inhibitor-containing well to the subsequent one. The final column was left without inhibitor as a control. Next, an overnight culture of the P. aeruginosa lasB-gfp and rhlA-gfp (ASV) strains, grown in LB medium at $37^{\circ} \mathrm{C}$ with shaking, were diluted to an optical density at $600 \mathrm{~nm}$ (OD600) of 0.2 , and $100 \mu \mathrm{Ll}$ of bacterial suspension was added to each well of the microtiter plate. As such, each compound was tested at concentrations ranging from 100 $\mu \mathrm{M}$ to $1.563 \mu \mathrm{M}$ across the plate, in a volume of $200 \mu \mathrm{L}$. The microtiter plate was incubated at $37^{\circ} \mathrm{C}$ in a Tecan Infinite 200 Pro plate reader (Tecan Group Ltd., Männedorf, Switzerland). GFP fluorescence (excitation at $485 \mathrm{~nm}$, emission at $535 \mathrm{~nm}$ ) and cell density (OD600) measurements were collected at 15-min intervals for at least $17 \mathrm{~h}$.

\section{Acknowledgements}

M.J. wishes to thank Mr Russell Gray of Marine Biodiscovery Centre, Aberdeen for running the NMR spectrometry. M. J. wishes to thank the EU. Seventh Framework Programme Project PharmaSea (grant agreement no-312184) for financial support for the collection of the marine sample. Also, This research is supported by the National Research Foundation, Prime 
Minister's Office, Singapore, under its Marine Science Research and Development Programme (award nos. MSRDP-P15 and MSRDP-P34).

\section{Author Contribution}

J. T. collected the marine sample and M.J., R.E, and J.T. designed the study. E. T. O. undertook the extraction, isolated, purification and structure elucidation of the compounds. O. T. assisted in the extraction of the sample. L. T. T. and N. P. K. performed the biological assays and analysed the data. E. T. O. drafted the initial manuscript, which was edited and approved by all the authors.

\section{Conflict of Interest}

No conflict of interest declared.

\section{Supporting Information}

Supplementary materials related to this article are supplied in a separate sheet.

\section{References}

Aminov, R. (2010). A Brief History of the Antibiotic Era: Lessons Learned and Challenges for the Future. Frontiers in Microbiology, 1.

Chen, F., Gao, Y., Chen, X., Yu, Z. and Li, X. (2013). Quorum Quenching Enzymes and Their Application in Degrading Signal Molecules to Block Quorum SensingDependent Infection. International Journal of Molecular Sciences 14, 17477-17500.

Chen, X., Chen, J., Yan, Y., Chen, S., Xu, X., Zhang, H. and Wang, H. (2018). Quorum sensing inhibitors from marine bacteria Oceanobacillus sp. XC22919. Natural Product Research 33, 1819-1823. 
Dai, L., Wu, T., Xiong, Y., Ni, H., Ding, Y., Zhang, W., Chu, S., Ju, S. and Yu, J. (2019). Ibuprofen-mediated potential inhibition of biofilm development and quorum sensing in Pseudomonas aeruginosa. Life Sciences 237, 116947.

Davies, D. (1998). The Involvement of Cell-to-Cell Signals in the Development of a Bacterial Biofilm. Science 280, 295-298.

Davey, M., Caiazza, N. and O'Toole, G. (2003). Rhamnolipid Surfactant Production Affects Biofilm Architecture in Pseudomonas aeruginosa PAO1. Journal of Bacteriology 185, 1027-1036.

Jakobsen, T., Bjarnsholt, T., Jensen, P., Givskov, M. and Høiby, N. (2013). Targeting quorum sensing in Pseudomonas aeruginosa biofilms: current and emerging inhibitors. Future Microbiology 8, 901-921.

Jiménez, C. and Crews, P. (1991). Novel marine sponge derived amino acids 13. Additional psammaplin derivatives from Psammaplysilla purpurea. Tetrahedron 47, 2097-2102.

Kim, D., Lee, I., Jung, J. and Yang, S. (1999). Psammaplin A, a natural bromotyrosine derivative from a sponge, possesses the antibacterial activity against methicillinresistantStaphylococcus aureus and the DNA gyrase-inhibitory activity. Archives of Pharmacal Research 22, 25-29.

Kupchan, S., Stevens, K., Rohlfing, E., Sickles, B., Sneden, A., Miller, R. and Bryan, R. (1978). Tumor inhibitors. 126. New cytotoxic neolignans from Aniba megaphylla Mez. The Journal of Organic Chemistry 43, 586-590

MarinLit Database: A Database of the Marine Natural Products Literature. Available online: http://pubs.rsc.org/marinlit (accessed on 7 November 2020). 
Ng, W. and Bassler, B. (2009). Bacterial Quorum-Sensing Network Architectures. Annual Review of Genetics 43, 197-222.

Oluwabusola, E., Tabudravu, J., Al Maqbali, K., Annang, F., Pérez-Moreno, G., Reyes, F. and Jaspars, M. (2020). Antiparasitic Activity of Bromotyrosine Alkaloids and New Analogues Isolated from the Fijian Marine Sponge Aplysinella rhax. Chemistry \& Biodiversity 17, e200335

Ortlepp, S., Sjögren, M., Dahlström, M., Weber, H., Ebel, R., Edrada, R., Thoms, C., Schupp, P., Bohlin, L. and Proksch, P. (2007). Antifouling Activity of BromotyrosineDerived Sponge Metabolites and Synthetic Analogues. Marine Biotechnology 9, 776785.

Pamp, S. and Tolker-Nielsen, T., 2007. Multiple Roles of Biosurfactants in Structural Biofilm Development by Pseudomonas aeruginosa. Journal of Bacteriology 189, 25312539.

Park, Y., Liu, Y., Hong, J., Lee, C., Cho, H., Kim, D., Im, K. and Jung, J. (2003). New Bromotyrosine Derivatives from an Association of Two Sponges,JaspiswondoensisandPoecillastrawondoensis. Journal of Natural Products 66, $1495-1498$.

Pesci, E., Milbank, J., Pearson, J., McKnight, S., Kende, A., Greenberg, E. and Iglewski, B. (1999). Quinolone signaling in the cell-to-cell communication system of 
Pseudomonas aeruginosa. Proceedings of the National Academy of Sciences 96, 11229-11234.

Rahim, R., Ochsner, U., Olvera, C., Graninger, M., Messner, P., Lam, J. and SoberónChávez, G. (2001). Cloning and functional characterisation of the Pseudomonas aeruginosa rhlC gene that encodes rhamnosyltransferase 2, an enzyme responsible for di-rhamnolipid biosynthesis. Molecular Microbiology 40, 708-718.

Rasmussen, T. and Givskov, M. (2006). Quorum-sensing inhibitors as antipathogenic drugs. International Journal of Medical Microbiology 296, 149-161.

Raymond, B.; Powell, N. (2019). We Must Follow These Five Rules To Avert An Antimicrobial Resistance Crisis. The Pharmaceutical Journal.

Rodriguez, A., Akee, R. and Scheuer, P. (1987). Two bromotyrosine-cysteine derived metabolites from a sponge. Tetrahedron Letters 28, 4989-4992.

Rutherford, S. and Bassler, B. (2012). Bacterial Quorum Sensing: Its Role in Virulence and Possibilities for Its Control. Cold Spring Harbor Perspectives in Medicine 2, a012427a012427.

Schuster, M. and Peter Greenberg, E. (2006). A network of networks: Quorum-sensing gene regulation in Pseudomonas aeruginosa. International Journal of Medical Microbiology 296, 73-81. 
Skindersoe, M.; Ettinger-Epstein, P.; Rasmussen, T.; Bjarnsholt, T.; Nys, R.; Givskov, M. (2008). Quorum Sensing Antagonism From Marine Organisms. Marine Biotechnology 10, 56-63.

Tabudravu, J., Eijsink, V., Gooday, G., Jaspars, M., Komander, D., Legg, M., Synstad, B. and van Aalten, D. (2002). Psammaplin A, a chitinase inhibitor isolated from the fijian marine sponge Aplysinella rhax. Bioorganic \& Medicinal Chemistry 10, 1123-1128.

Tintillier, F., Moriou, C., Petek, S., Fauchon, M., Hellio, C., Saulnier, D., Ekins, M., Hooper, J., Al-Mourabit, A. and Debitus, C. (2020). Quorum Sensing Inhibitory and Antifouling Activities of New Bromotyrosine Metabolites from the Polynesian Sponge Pseudoceratina n. sp. Marine Drugs 18, 272.

Wagner, V., Bushnell, D., Passador, L., Brooks, A. and Iglewski, B. (2003). Microarray Analysis of Pseudomonas aeruginosa Quorum-Sensing Regulons: Effects of Growth Phase and Environment. Journal of Bacteriology 185, 2080-2095.

Zhao, X., Yu, Z. and Ding, T. (2020). Quorum-Sensing Regulation of Antimicrobial Resistance in Bacteria. Microorganisms 8, 425. 
bioRxiv preprint doi: $\mathrm{https}$ //doi.org/10.1101/2021.01.22.427779; this version posted January 23, 2021. The copyright holder for this preprint (which was not certified by peer review) is the author/funder, who has granted bioRxiv a license to display the preprint in perpetuity. It is made available under aCC-BY-NC-ND 4.0 International license.
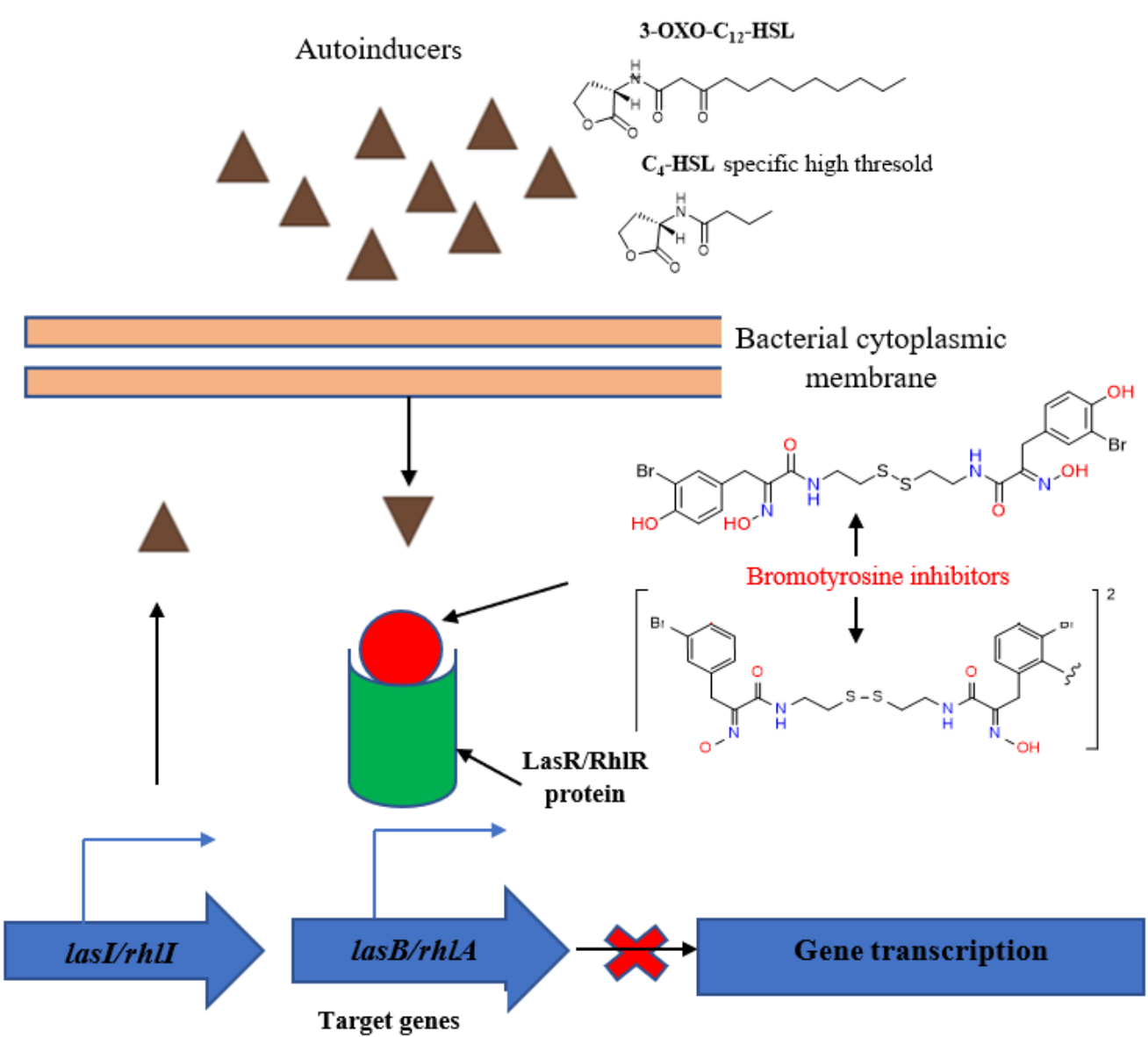